\title{
Associated Complications In Beta Thalassemia Patients
}

\author{
${ }^{1}$ Kirti Grow, ${ }^{2}$ Pankaj Abrol, ${ }^{3}$ Minakshi Vashist,${ }^{4}$ Ritu Yadav, ${ }^{5}$ Shiksha \\ Sharma \\ ${ }^{1,5}$ Research Scholars, ${ }^{2}$ Professor, Pediatrics, Pt. BD Sharma University of Health Sciences, Rohtak. \\ ${ }^{3}$ Professor, ${ }^{4}$ Assisstant Professor, Deptt. of Genetics, MD University, Rohtak,
}

\begin{abstract}
Every year approximately 100,000 children with Thalassemia major are born world over, of which 10,000 are born in India. The combination of regular blood transfusions and chelation therapy has dramatically increased the life expectancy of thalassemics into 4th \& 5th decades of life. On the other hand, frequent blood transfusion has also led to iron overload with many complications including endocrinopathies, behavioral and neurotic problems, growth failure etc. In the present study analysis of beta thalassemia major cases was done to determine the frequency and extent of complications associated with thalassemia. Two hundred thirty one patients of beta thalassemia were studied in the present investigation. It is concluded that commonest complication of beta thalassemia major is growth failure. Other complications are also not uncommon and involve liver, heart and endocrine glands. This study would help in early detection of the associated complications in beta thalassemia patients which would be quite helpful to reduce the burden of disease through preventive measures.
\end{abstract}

Key Words: Associated complications, beta thalassemia, growth failure, cardiac complications and transfusion related complications.

\section{Introduction}

India is an ethnically diverse country with an approximate population of 1.2 billion. $\beta$-thalassemia is the commonest single-gene disorder in the Indian population The frequency of beta-thalassemia trait ( $\beta T T$ ) has variously been reported from $<1 \%$ to $17 \%$ and an average of 3.3. It is characterized by reduced synthesis of $\mathrm{Hb}$ subunit $\beta$ ( $\mathrm{Hb} \beta$ chain) that results in microcytic hypochromic anemia, an abnormal peripheral blood smear with nucleated red blood cells and reduced amounts of $\mathrm{Hb}$ A. Individuals with thalassemia major have severe anaemia and hepatosplenomegaly; they usually come to medical attention within first two years of life. Without treatment, affected children have severe failure to thrive and shortened life expectancy. Individuals with thalassemia intermedia present later and have milder anaemia that only rarely requires transfusion. These individuals are at risk for iron overload secondary to increased intestinal absorption of iron as a result of ineffective erythropoisis. Every year approximately 100,000 children with Thalassemia major are born world over, of which 10,000 are born in India [1]. It is estimated that there are about 65,000-67,000 $\beta$-thalassemia patients in our country with around 9,000-10,000 cases being added every year [2-8]. The carrier rate for $\beta$ thalassemia gene varies from 1 to $3 \%$ in Southern India to $3 \%$ to $15 \%$ in Northern India. Certain communities in India, such as Sindhis and Punjabis from Northern India, Bhanushali's, Kutchis, Lohana's from Gujarat, Mahar's, Neobuddhist's, Koli's and Agri's from Maharashtra, \& Gowda's and Lingayat's from Karnataka etc. have a higher carrier rate[4,5]. The combination of regular blood transfusions and chelation therapy has dramatically increased the life expectancy of thalassaemics into 4 th $\& 5^{\text {th }}$ decades of life. On the other hand, frequent blood transfusion has also led to iron overload with many complications including endocrinopathies, behavioral and neurotic problems, growth failure, cardiovascular problems, liver disease, gonadal dysfunction and delayed puberty. Frequent blood transfusion can also lead to increased chances of transfusion related infections. In the present study analysis of beta thalassaemia major cases was done to determine the frequency and extent of complications associated with thalassemia.

\section{Material and Methods}

All the beta thalassemic patients were investigated to confirm the diagnosis of beta thalassaemia major with $\mathrm{Hb}$, peripheral smear, $\mathrm{Hb}-\mathrm{F}$ assay and $\mathrm{Hb}$-electrophoresis. Patients were labelled as having growth failure when their weights were below -2 standard deviations for age and sex.

Statistical Method- Results were analyzed by descriptive statistical methods, including percentage, mean, two way ANOVA and Chi-Square test etc. 


\section{Results}

Two hundred thirty one patients of beta thalassemia were studied in the present investigation. Male to female ratio was 2.6: 1 and majority were above 10 years of age (61.8\%) (Table 1). Age of the youngest patient at diagnosis was 4 months and oldest patient of the study was 28 years old. Patients belonged to nine communities (Punjabi, Sunar, Jaat, Brahman, Ahir, Khaati, Baniya, Chauhan and Sikh). Punjabis were found to have the highest frequency (31\%) of $\beta$ thalassemia followed by Jaat (11.6\%), Brahman (8.3\%) and Sunar (8\%). High frequency $(35.48 \%)$ of consanguinity was noticed in patients belonging to Punjabi community. As a corollary, the projected incidence of $\beta$-thalassaemia major in newborn babies greatly varied by the subcastes of the parents. Around two third (75\%) of total patients were from Urban region while only $25 \%$ of them belong to rural population.

Table 1: Age and Sex Distribution

\begin{tabular}{|c|c|c|c|c|}
\hline Age/Sex & $\mathbf{5}$ years & $\mathbf{5 - 1 0}$ years & $\mathbf{\geq 1 0}$ years & Total \\
\hline Male & 59 & 49 & 60 & 168 \\
\hline Female & 17 & 21 & 25 & 63 \\
\hline Total & 76 & 70 & 85 & 231 \\
\hline
\end{tabular}

Most of the patients (51\%) were diagnosed to be $\beta$ thalassemic major before 8 months of age and $38 \%$ of cases were diagnosed between 8 months to 5 years of age. Very few cases (12\%) could be detected after 5 years of age. Due to quite high frequency of foetal loss in mothers of $\beta$ thalassemic patients, it has come out as a risk factor in $\beta$ thalassemia. It was found that $40.9 \%$ cases showed foetal loss in mothers of $\beta$ thalassemic patients. Two way ANOVA on the sample population of beta thalassemia (major) in different age groups and gender was applied and the interaction of age and gender as a factor was studied. Statistical calculations revealed statistically significant values for male and female ratio $\mathrm{CI}=95 \%,(\mathrm{df}=1, \mathrm{p}=0.013)$. Whereas age alone as a factor was found less significant $(\mathrm{CI}=95 \%, \mathrm{df}=2, \mathrm{p}=0.394)$.

Complications were observed in a total of $176(76.1 \%)$ patients. Some patients were having more than one complication. Commonest complication was growth failure and was observed in 81 (46\%) patients (Table 2). Next common were cardiac complications and were observed in 41 patients $(23.3 \%)$. Hepatic enzymes were raised in 12 patients $(6.8 \%)$. Endocrine complications were found in $30(17.1 \%)$ patients. Transfusion related infections such as Hepatitis B were found in 12 (6.8\%) cases. All complications (except growth failure) were observed in children over 5 years of age.

Table 2: Complications

\begin{tabular}{|l|l|l|}
\hline 1. & Growth Failure & $46 \%$ \\
\hline 2. & Hepatic & $6.8 \%$ \\
\hline 3. & Cardiac & $23.3 \%$ \\
\hline 4. & Transfusion related infections (Hepatitis B) & $6.8 \%$ \\
\hline 5. & Endocrine & $17.1 \%$ \\
\hline
\end{tabular}

Table: 3 Association between different complications and Sex ratio.

\begin{tabular}{|l|l|l|l|l|l|}
\hline Complications & $\begin{array}{l}\text { Growth } \\
\text { Failure }\end{array}$ & Hepatic & Cardiac & $\begin{array}{l}\text { Transfusion } \\
\text { related infections } \\
\text { (Hep B) }\end{array}$ & $\begin{array}{l}\text { Endocrine } \\
\text { Sex }\end{array}$ \\
\cline { 1 - 5 } & & & & 7 & 18 \\
\hline Female & 54 & 6 & 31 & 5 & 12 \\
\hline
\end{tabular}




\section{* Significant at $\mathbf{p}<0.5$}

Statistical analysis using Chi square revealed significant values for the association of complications and sex ratio in beta thalassemia major patients $\left(\chi^{2}=3.862, \mathrm{df}=4, \mathrm{p}=0.425\right)$ (Table 3 ).

\section{Discussion}

Over the past three decades, regular blood transfusions and iron chelation has dramatically improved the quality of life and transformed thalassemia from a rapidly fatal disease in early childhood to a chronic disease compatible with prolonged life. Today life expectancy varies between 25-55 years, depending on the compliance with medical treatment. Despite increased life expectancy, complications keep arising. These relate to inadequate transfusions, transfusion-related infections, allosensitization, iron-overload related cardiac, endocrine and liver disturbances and toxicities of iron chelators. Many of these problems are strongly age dependent. In our study the growth failure $(49.4 \%)$ was found to be the most common complication. It is due to growth hormone neuro-secretary disturbance and secondary growth hormone insensitivity $[9,10]$. Chronic anaemia, congestive cardiac failure, haemosiderosis and other endocrine and metabolic disturbances may also be contributory factors[11]. Similar figures have been reported by others as well [10]. Next common complication is Cardiac complications (in $23.3 \%$ of cases). This figure is higher than $4.8 \%$ reported from USA [12]. Heart disease is the most important complication and the main determinant of survival. It is responsible for more than half of the deaths [12,13].It may take the form of cardiomyopathy, pulmonary hypertension, heart failure, arrhythmias, pericarditis and myocarditis. Although iron overload is the main cause but other factors; genetic, immune or infective, may also be important [14]. Hepatic complications were found to be less significant complications and our results $(6.8 \%)$ were in accordance with earlier studies $[15,16]$. Endocrine complications include diabetes mellitus, hypothyroidism, hypoparathyroidism, hypogonadism and delayed puberty. These complications have contributed little to morbidity and mortality in the past; however as a result of increased longevity, these have become more common and contribute significantly to the morbidity in these patients [17]. Endocrine complications along with osteoporosis, trace elements deficiency and other metabolic disturbances also lead to growth failure and short stature $[9,10]$. Hypogonadism is the most frequent endocrine complication in patients with thalassemia and is an important cause of growth retardation in adolescence. $17.1 \%$ of patients showed endocrine complications. This figure is quite less than earlier reports. This figure is lower than $57 \%$ reported by Satwani et al and $88 \%$ reported by Shamshirsaz et al $[18,9]$. In a multicentre study from Italy involving 1861 patients, hypogonadism was present in $47 \%$ of girls older than 15 years of age and secondary amenorrhoea in $23 \%$, menstrual irregularity in $14 \%$ and arrest of sexual maturation in $13 \%$. Hypogonadism was present in half the male patients. Similarly high prevalence of disordered puberty has been reported in other studies [19-22]. Abnormal sexual maturation and hypogonadism were reported in $36 \%$ of the male and $67 \%$ of female patients from Australia [20].

\section{Conclusion}

Despite advances in medical therapy, growth retardation and other complications continue to be problems observed in transfusion-dependent patients with thalassemia major. The survival of patients with thalassemia major is good and improving, but the prevalence of severe complications is still high. It is concluded that commonest complication of beta thalassaemia major is growth failure. Other complications are also not uncommon and involve liver, heart and endocrine glands. Satisfactory cost-effective treatment for beta thalassaemia major as yet is not available, other than bone marrow transplantation. This study would help in early detection of the associated complications in beta thalassemia patients which would be quite helpful to reduce the burden of disease through preventive measures. Until the achievement of this goal, establishing centers for palliative and curative treatment of beta thalassaemia is important.

\section{Acknowledgement}

The authors are thankful to Pt. B.D. Sharma University of Health Sciences, parents and guardians for providing kind cooperation and information. The work supported in parts by CSIR SRF (Council for Scientific and Industrial Research Senior Research Fellowship) and UGC (University Grant Commission Research Project grant \& project Fellowship).

\section{References}

[1]. N Thacker. Prevention of thalassemia in India, Indian Pediatrics, 44, 2007, 647-48.

[2]. DJ Weatherall, JB Clegg. The Thalassemia Syndromes (Oxford: Blackwell Scientific Publications, 2001).

[3]. HM Yaish. Thalassemia. http://www.emedicine.com/ PED/topic2229.htm Accessed 6th August 2007.

[4]. IC Verma, VP Choudhry, PK Jain. Prevention of thalassemia: A necessity in India, Indian J Pediatr, 59, 1992, 649-654. 
[5]. M Manglani, MR Lokeshwar, VG Vani, N Bhatia, V. Mhaskar. 'NESTROFT' - an effective screening test for b-Thalassemia trait, Indian Pediatr, 34, 1997, 703 - 708.

[6]. N Ghotbi, T Tsukatani. An economic review of the national screening policy to prevent thalassemia major in Iran. From: www.kier.kyoto-u.ac.jp/DP/DP562. Accessed 6th August 2007.

[7]. JT Ostrowsky, A Lippman, CR Scriver. Cost-benefit analysis of a thalassemia disease prevention program, Am J Public Health, 75 , 1985, 732-736.

[8]. World Health Organization: Human Genetics Programme. Division of Communicable Diseases. Community control of hereditary anaemias: memorandum for a WHO meeting. Bull WHO, 61, 1983, 63-80.

[9]. A Shamshirsaz, MR Bekheirnia, M Kanger et al. Metabolic and endocrinologic complications in beta-thalassemia major: A multicenter study in Tehran, BMC Endocrine Disorders, 3 (4), 2003, 23-34.

[10]. CK Low Louis. Growth of children with beta thalassemia major (Editorial), Indian J Pediatr, 72 (2), 2005, 159-64.

[11]. AS Sharada. Thalassemia and related hemoglobinopathies. Indian J Pediatr, 72 (4), 2005, 319-24.

[12]. A Aessopos, D Farmakis, S Deftereous et al. Thalassemia Heat Disease- A comparative evaluation of thalassemia major and thalassemia intermedia, Chest, 127, 2005, 1523-30.

[13]. C Borgne-Pignatti, MD Cappellini, P De Stefano, GC Del Vecchio, GL Forni, MR Gamberini, et al. Survival and complications in thalassemia, Ann N Y Acad Sci, 1054, 2005, 40-47.

[14]. DT Kremastinos, P Flevari, M Spyropoulou, H Vrettou, D Tsiapras, CG Stavropoulos-Giokos. Association of heart failure in homozygous beta thalassemia with the major histocompatibility complex, Circulation, 100, 1999, 2074-78.

[15]. V Perifanis, K Tziomalos, I Tsatra, S Karyda, K Patsiaoura, M Athanassiou-Metaxa. Prevalence and severity of liver disease in patients with beta thalassemia major. A single-institution fifteen year experience (letter). Haematologica, 90, 2005, 1136-38.

[16]. D Prati, M Maggioni, S Milani, M Cerino, P Cianciulli, G Coggi et al. Clinical and histological characterization of liver disease in patients with transfusion-dependent beta thalassemia. A multicenter study of 117 cases. Haematologica, 89, 2004, 1179-86.

[17]. S Mohammadian, HR Bazrafshan, A Sadeghi-Nejad. Endocrine gland abnormalities in thalassemia major: a brief review, Pediatr Endocrinol Metab, 16, 2003, 957-64.

[18]. H Satwani, J Raza, M Alam, A Kidwai. Endocrine complications in thalassemias; Frequency and association with ferritin levels, $P$ P J, 29(2), 2005, 113-9.

[19]. EYW Kwan, ACW Lee, AMC Li et al. A cross-sectional study of growth, puberty and endocrine function in patients with thalassemia major in Hong Kong, J Pediatr Child Health, 31, 1995, 83-87.

[20]. CP Rodda, ED Reid, S Johnson, J Doery, R Matthews, DK Bowden. Short stature in homozygous 13-thalassemia is due to disproportionate truncal shortening. Clin Endocrinol, 42, 1995, 587-592.

[21]. CK Low, YW Kwan, PT Cheung et al. The effect of platyspondyly and pubertal growth spurt on the stature of patients with 13thalassaemia major. Chinese Med J, 111, 1998, 731-735.

[22]. KE Oerter, GA Kamp, PJ Munson, AW Nienhaus, FG Cassorla, PK Manasco. Multiple hormone deficiencies in children with hemochromatosis. J Clin Endocrinol Metab, 76, 1993, 357-361. 